\title{
The use of Augmentative and Alternative Communication apps for the iPad, iPod and iPhone: An overview of recent developments \\ Dr Jill Bradshaw. J.Bradshaw@kent.ac.uk
}

\section{Introduction}

Communication takes place within a communication partnership and involves the exchange of ideas (Bartlett and Bunning, 1997). All communication exchanges involve a degree of interpretation and, for people with severe communication disabilities, communication partners may need to take greater responsibility for the interpretation of communication acts, particularly when people have a limited range of communicative signals (Grove et al, 1999). People with severe disabilities are often unable to use spoken communication and so need additional means of communication such as Augmentative and Alternative Communication (AAC) (Sigafoos et al., 2007). It is estimated that 365000 people in the UK have a need for AAC (Blackstone, 1990). The United Nations Convention on the Rights of Persons with Disability (United Nations, 2006) make explicit that people have the right to be able to access whichever form of communication they choose and that this includes the use of AAC.

Whilst AAC systems are able to support users to construct and share ideas with communication partners, AAC users may still face difficulties (Baxter et al, 2012b). These include prevailing attitudes that 'privilege spoken languages and deny the value of alternatives' (von Tetzchner and Grove, 2003, p 1). However, recent developments in communication applications (apps) for the iPad, iPod and iPhone may provide a more socially 'accepted' means of communication (e.g. see www.speechbubble.org.uk/device/iPad/).

Glenda Watson Hyatt, who uses an iPad as an AAC points out that communication partners are much more familiar with iPad technology and so are not discouraged from 
communicating with her, as they might be if she was using a more traditional communication aid (Watson Hyatt, 2011):

This article will provide a brief overview of AAC before outlining some of the developments in the use of communication apps.

\section{What do we mean by functional communication?}

Functional communication is that which occurs in real life settings (rather than in 'therapy sessions'), results in real consequences (is successfully used to exchange ideas) and include spontaneous use (is not limited to only responding or only communicating in set situations) (Rowland and Schweigert, 1993). Functional communication should be used to enable the individual to express their wants and needs and to share information (Light, 1997). Whilst we may be used to thinking primarily about one mode of communication (e.g. the person in question uses speech, or the person uses signed communication, or the person uses a voice output communication aid) communication is a multi-modal process (Light, 1988). We all use a variety of means of communication, such as body language, gesture, facial expression to take part in communication exchanges.

\section{Augmentative and Alternative Communication}

AAC systems can be broadly categoried as aided (e.g. Voice Output Communication Aids VOCA, also known as Speech Generating Devices - SGD and light tech devices such as symbols boards) and unaided (e.g. manual sign systems). Aided communication systems can be further separated into those where communication is dependent on selection (of for example a symbol on a board) and exchange based systems where symbols are given to a communicative partner, an act considered functionally equivalent to speaking a word or phrase (Sigafoos et al., 2007). 
AAC may be used in three main ways (von Tetzchner and Martinsen, 2000). Some people may need AAC if they have comprehension skills which are in advance of their expressive skills. For this group of people, the issue is that they have more to communicate about than their current means of expression will allow. For another group of people, the AAC support may be a temporary means or may only be needed in some specific situations. Lastly, AAC may be needed for both expressive communication and for comprehension.

\section{Communicative Competence}

Communicative competence (Light, 1989) occurs across a continuum and involves linguistic, operational, social and strategic competence. This involves thinking about issues such as:

- Does the person have functional communication skills that are adequate in any particular environment?

- How well does the person use their particular linguistic code? Does the communication system meet daily communication needs?

- How proficient are they in using the physical or technical skills that are required to produce the communication output (e.g. how easy is it to access the switch, or to physically produce the hand shape required for the signed communication)?

- How does the person manage the social skills that are required to take part in the interaction?

- Finally, what compensatory strategies does the person have to manage their communication difficulties? How are they able to adapt their communication (or other) skills when difficulties are encountered? 
Light (1989) describes these areas as interacting with one another. If we imagine that each person has a set of resources that can be devoted to communication at any particular time, then it is sensible to provide a communication system that presents the least challenges to operational competence (is as easy as possible for the person to use) but provides the greatest possible opportunities for the person to take part in functional daily communication. This will usually mean making compromises. For example, the number of symbols used may need to be limited, so that the operational demands placed on the person are reduced but this in turn may limit the number of phrases that the individual is able to express.

\section{Barriers to the implementation and use of high-technology AAC}

Recent research reviews (Baxter et al, 2012a;b) highlight the lack of evidence around the use of high-technology AAC devices, which make it difficult for practitioners to make decisions during the implementation of AAC interventions. There is also research suggesting that the functional use of devices may be limited, with evidence to suggest that though AAC users were able to demonstrate use of the communication aid in some settings (e.g. during therapy sessions) these gains did not necessarily transfer to use in every day settings (Jacobs, 2004).

In their thematic synthesis (Baxter et al, 2012b) identified a number of factors which influenced the implementation and use of high technology AAC. These included:

- Ease of use. Aspects such as the time taken to programme the system were important (Bailey et al, 2006). This corresponds well with the technical competence described by Light (1997). Parents also reported finding the AAC systems difficult to use (Marshall and Goldbart, 2008).

- Reliability. Breakdown and length of time taken to repair were reported as barriers (Kent-Walsh and Light, 2003). 
- Availability of technical support. It was often difficult to access any technical support needed (Smith and Connolly, 2008).

- The voice or language of the device. This included the limited vocabulary (Bailey et $a l, 2006)$, and factors to do with voice, such as embarrassment felt by young people that the voice output was not their own voice (Clarke et al, 2001).

- Making decisions. Users and users' families reported varying degrees of involvement in decisions made about the choice of high-technology AAC device.

- Time generating a message. The slowness of the device was often reported as problematic. Lund and Light (2007) point out that, to be really successful, the device needs to be able to 'produce' the message in time with the thoughts of the person using it.

- In addition, positive family expectations were helpful. Familiar adults were general seen as positive communication partners (Marshall and Golbart, 2008).

\section{The iPhone, iPad and iPod as AAC devices.}

Detailed information can be found at www.speechbubble.org.uk/device/ amongst others.

These devices are transformed into communication aids via the addition of AAC apps (described later). The iPad has a larger screen than the iPod and iPhone. This means that it is possible to allow more items on the screen, or less items with larger symbols or a greater space between each symbol. For example, for apps which use a grid system (see later) the iPad is capable of having up to 64 onscreen items, whereas the iPod and iPhone can only support 24.

Brady (2011) writes that these devices offer many advantages over more traditional communication aids. Not only are they 'super-cool' which promotes use and acceptance 
(these devices may even be coveted by others) they are also much cheaper than traditional communication aids and more portable. Cost is likely to be a particular factor in the current economic climate, especially as previous research has identified funding issues as a barrier to the implementation and use of high-technology communication aids (McNaughton and Bryen, 2007). These devices are also easy to use and do not require a mouse or keypad. The apps to enable these devices to be used for communication are also easily available for download and many are inexpensive.

Some of the factors identified by Baxter et al (2012b) as potential barriers to the use of communication aids (described above) may be addressed by the introduction of the iPad, iPod and iPhone. For example, these devices may score more highly in ease of use, reliability, availability of technical support, family perception and support, though further research would be needed to determine whether this is indeed the case.

\section{What about people with physical disabilities?}

As the iPad, iPod and iPhone have all been designed for people who do not have any difficulty in using their hands, these devices may presently have limited use for people who need alternative access. There is currently little option for people with physical disabilities who require access via head pointing, tracking or eye gaze (Chappel, 2011) (though see below for some more recent apps that have been designed with eye gaze in mind).

\section{AAC Apps}

The development of apps for AAC is very rapid and as of August 2012, the website AppsForAac.net listed 244 apps, of which 54 were free. This site was designed by an Occupational Therapist (Will Wade), during the time he worked at the ACE Centre in 
Oxford. The apps are described on this site and are divided into various categories according to their main function. Some apps encompass more than one category.

\section{Categories of apps}

- Text to speech - these apps convert text to spoken communication and are probably the largest category of apps for communication.

- Symbols in grid based system - a number of symbols are used within grid systems on the screen, with each symbol activating a spoken word or phrase.

- Word predictor - these systems have a word predictor so that possible words are suggested when you start typing. These words are then converted into speech.

- Phrases - some apps have set phrases e.g. apps which have symbol sets of emotions. Some of these have set phrases, whilst others allow phrases to be changed.

- Eye pointing - these apps are designed for people who communicate using eye direction. The communication partner then follows the direction of the eye point to the symbol.

- Photo story (or visual story) - these offer the ability to take photos, use these in a slide show and then add in speech to tell the story.

- Picture Exchange Communication System - apps which use the PECS as a means of communication.

The speech output used varies. Some apps use synthesised voices (e.g. choice of male, female, some regional accents and some children's voices available) and others have the ability to record a voice (see www.appsforaac.net for examples). Apps also use a range of different symbol systems, with the ability to use photos also commonly available. 
Some examples of the use of AAC apps

Symbol Grid Based System

The Prologue2go (Sennott and Bowker, 2009) is the most popular AAC grid based system (Mirendar, 2009). The app can be used on the iPad, iPod and iPhone. It has a range of voices (including English and American male and female child's voices). The app has two prestored vocabularies, which are based on linguistic research. These are basic communication and core words which facilitate fast sentence building. There is an option for multi-user support. This allows users to easily switch between different vocabularies or the device to be easily switched between users. Kagohara et al (2012) present a case study of a successful intervention using Prologue2go with an iPod Touch device. However, this demonstrated success in being able to activate the symbols on the device rather than improvements in the functional use of the iPod as an aid to communication. Indeed, the authors describe a period during the intervention where the person did not have access to the device for a period of four weeks due to a school vacation.

Photo story (or visual story) apps

Good examples of these include using these apps for social stories ${ }^{\mathrm{TM}}$ (Gray and Garand, 1993) or for communication passports (Millar and Aitken, 2003). Social stories accurately describe and explain social information in an accessible format. Communication passports were developed as a means of presenting important information about a person, when that person was not able to communicate for themselves. They contain, in an accessible format, assessment information and record anything that it could be important for other people to know. In the past, these have been produced in a paper format. It is possible, using many of the available apps to create both social stories and communication passports using the iPad, iPod or iPhone. As the passport or social stories are then stored on the device, they are 
readily available and can be easily adapted to update new information or to create a new social story when needed. See also www.callscotland.org.uk/Resources/Information-Sheets/

\section{Conclusion and a cautionary note}

A recent review of published interventions using high-technology communication aid devices (Baxter et al, 2012a;b) found that, while the use high-technology AAC has led to improvements in the communicative ability of people with communication difficulties, there is a great deal of variation in the outcomes of published research and a need for more highquality research in this area. They suggest that much greater attention to individual characteristics is needed in order to make decisions about who will benefit most and which type of AAC may be best suited to individual needs.

Despite the potential of the AAC apps described above, we also need to remember that more 'traditional' communication aids may offer a better option for some people who have a need to use AAC. For example, Stevens (2011) comments that the combination of an iPad and Lightwriter produced the best results for him. The iPad did not replace his need for a Lightwriter as it was less robust and not as easy to type with. For other people, lowtechnology aids (which are also cheaper) may offer advantages over high-technology aids (Iacono et al, 2011; Mirenda, 2001). McBride (2011) notes the danger that, as devices such as the iPad are relatively low cost and easily available, they may be introduced prematurely, before the needs of the individual are assessed. For example, in a survey around the use of the iPad device, only just over half the people using these devices had had an assessment of whether this might be the most suitable means of AAC (Scherz, Dutton, Steiner, \& Trost, 2010). 
The key here seems to be that each person needs an individual assessment to determine their specific communication needs and to see which (if any) AAC devices are likely to meet these needs (Hershberger, 2011). Gosnell et al (2011) suggest that we are in danger of trying to fit the person to the device and the app, rather than the app and the device to the person. It is also important to note that, whilst there are many examples of success stories, apps provide an alternative or augmentative 'form' or 'mode' of communication and as such, are only a small part of what communication is about.

\section{Some Useful Resources}

The information available online is vast. This is a small selection of what is available. Most have very useful links to other sites:

- $\quad$ www.ace-centre.org.uk - offers help and support for people with complex physical and communication difficultieswww.AppsForAac.net - site complements the information which is on SpeechBubble and provides information on the apps which are currently available.

- $\quad$ www.callscotland.org.uk - work in Scotland carrying out research and helping people to use assistive technology. See also www.callscotland.org.uk/Resources/Apps for information about apps. Various information sheets are also available for download.

- $\quad$ www.communicationmatters.org.uk - aims to support all those who have difficulties communicating because they are not able to use, or have difficulties using, spoken communication

- $\quad$ www.Speechbubble.org.uk - Gives information on a wide variety of communication aid technology for the UK 
The following websites provide information on a range of apps which have been used with and by people with ASC.

- http://www.iautism.info/en/2010/09/20/application-list/

- http://touchautism.com/Autism+Apps.aspx -

\section{References:}

Bartlett, C. \& Bunning, K. (1997). The importance of communication partnerships: a study to investigate the communicative exchanges between staff and adults with 1 earning disabilities. British Journal of Learning Disabilities, 25, 148-153.

Baxter, S., Enderby, S., Evans, P. And Judge, S. (2012a) Interventions using hightechnology communication devices: A state of the art review. Folia Phoniatrica et Logopaedica, 64, 137-144

Baxter, S., Enderby, S., Evans, P. And Judge, S. (2012b) Barriers and facilitators to the use of high-technology augmentative and alternative communication devices: A systematic review and qualitative synthesis. International Journal of Language and Communication Disorders, 47, 2, 115-129.

Blackstone, S. (1990) Population and practices in AAC. Augmentative Communication News, 3, 1-3.

Brady, L.J. (2011) Apps for Autism: An Essential Guide to Over 200 Effective Apps for Improving Communication, Behavior, Social Skills and More! Texas: Future Horizons Inc.

Chappel, D. (2011). The evolution of augmentative communication and the importance of alternate access. Perspectives on Augmentative and Alternative Communication, 20, 34-37.

Clarke, M., McConachie, M., Price, K, and Wood, P. (2001) Views of young people using augmentative and alternative communication systems. International Journal of Language and Communication Disorders, 36, 107-115.

Gosnell, J., Costello, J. and Shane, H. (2011) There isn't always an App for that! Perspectives on Augmentative and Alternative Communication, 20, 7-8.

Gray, C. and Garand, J.D. (1993) Social Stories: Improving responses of students with autism with accurate social information. Focus on Autistic Behavior 8, 1-10.

Grove, N., Bunning, K., Porter, J. \& Olsson, C. (1999a) See what I mean: Interpreting the meaning of communication by people with severe and profound intellectual disabilities. Journal of Applied Research in Intellectual Disabilities, 12, 190-203.

Hershberger, D. (2011) Mobile technology and AAC Apps from an AAC developer's Perspective. Perspectives on Augmentative and Alternative Communication, 20, 2833.

Iacona, T., Lyon, K. and West, D. Non-electronic communication aids of people with complex communication needs. International Journal of Speech Language Pathology. 13, 399-410.

Kagohara,D.M., van der Meer, L., Achmadi, D., Green, V.A., O’Reilly, M.F. Mulloy, A., Lancioni, G.E., Lang, R. and Sigafoos, J. (2011) Behavioral Intervention Promotes Successful Use of an iPod-Based Communication Device by an Adolescent With Autism. Clincal Case Studies, 9, 5, 328-338. 
Kent-Walsh, J.S. and Light, J. (2003) General education teachers' experiences with inclusion of students who use augmentative and alternative communication. Augmentative and Alternative Communication, 19, 104-124.

Light, J. (1989) Toward a definition of communicative competence for individuals using Augmentative and Alternative Communication systems. Augmentative and Alternative Communication, 5, 137-144.

Light, J. (1997) "Communication is the essence of human life": Reflections on communicative competence. Augmentative and Alternative Communication, 13, 6170.

Lund, S.K. and Light, J. (2007) Long-term outcomes for individuals who use augmentative and augmentative communication: Part III - contributing factors. Augmentative and Alternative Communication, 23, 323-335.

Marshall, J, and Goldbart, J. (2008) 'Communication is everything I think.' Parenting a child who needs augmentative and alternative communication AAC: Augmentative and Alternative Communication. 43, 77-98.

McBride, D. (2011) AAC evaluations and new mobile technologies: asking and answering the right questions. Perspectives on Augmentative and Alternative Communication, 20, 9-16.

McNaughton, D. and Bryen, D. (2007) AAC technologies to enhance participation and meaningful societal roles for adolescents and adults with developmental disabilities who require AAC. Augmentative and Alternative Communication. 23, 217-229.

Millar, S. and Aitken, S (2003) Personal Communication Passports: Guidelines for good practice, CALL centre: University of Edinburgh

Mirenda, P. (2001) Autism, augmentative communication and assistive technology: what do we really know? Focus on Autism and Other Developmental Disabilities, 16, 141151.

Mirenda, P. (2009). Promising interventions in AAC for individuals with autism pectrum disorders. Perspectives on Augmentative and Alternative Communication, 18, 112113.

Rowland, C. \& Schweigert, P. (1993) analyzing the communication environment to increase functional communication. Journal for the Association of Persons with Severe Handicaps, 18, 161-176.

Sennott, S., \& Bowker, A. (2009). Autism, AAC, and Proloquo2Go. Perspectives on Augmentative and Alternative Communication, 18, 137-145.

Scherz, J., Dutton, L., Steiner, H., \& Trost, J. (2010, November). Smartphone applications useful in communication disorders. Miniseminar presented at the 2010 annual meeting of the American Speech-Language-Hearing Association, Philadelphia, PA. Cited in McBride (2011)

Sigafoos, J., Ganz, J. B., O'Reilly, M. F., Lancioni, G. E. \& Schlosser, R. (2007) Assessing correspondence following acquisition of and exchange-based communication system. Research in Developmental Disabilities, 28, 71-83.

Smith, M. and Connolly, I, (2008) Roles of aided communication: perspectives of adults who use AAC. Disability and Rehabilitation Assistive Technology, 3, 260-273.

Stevens, S. (2011) Have you seen my new mobile phone? Merging AAC with mobile telephony. Communication Matters, 25, 3, 5-7.

United Nations (2006) Convention on the Rights of Person with Disabilities. New York: United Nations

Von Tetzchner, S. \& Grove, N. (Eds.) (2003) Augmentative And Alternative Communication: Developmental Issues, London, Whurr. 
Von Tetzchner, S. \& Martinsen, H. (Eds.) (2000) Augmentative and Alternative Communication, London, Whurr Publishers Ltd.

Watson Hyatt, G. (2011) The iPad: A cool communicator on the go. Perspectives on Augmentative and Alternative Communication, 20, 24-27. 